\title{
VODENJE EVIDENC O PROCESU IZOBRAŽEVANJA
}

Primer podjetja SRC.SI

\section{POVZETEK}

$V$ prispevku je prikazan sodoben in učinkovit pristop k obvladovanju vseh aktivnosti in podatkoy za podporo procesu izobraževanja. Gre za elektronsko podporo, katere cilj je pridobivanje relevantnilh informacij za podporo odločanju vodstva ter za vodenje in planiranje podatkov o izobraževanju (vodenje evidence o izobraževanju) za vsakega zaposlenega posebej ter za use zaposlene po enotah oz. na ravni cele organizacije. Tako lahko kdorkoli in kadarkoli pridobi v najkrajšem možnem času točne podatke o izobraževanju (plani, stroški, izvedba, ure in dnevi izobraževanja, proces aktivnosti, poročila, ocene in ankete) za različna področja izobraževanja (splošno-funkcionalno izobraževanje, usposabljanje (pripravništvo, poskusno delo, prerazporeditev), ciljno usposabljanje in študij ob delu).

Ključne besede: izobraževanje, podatki, informacije, elektronski procesi

Stevilnih potreb zaposlenih in vodstva $v$ sodobno organiziranih podjetjih ni mogoče več reševati sproti, $\mathrm{z}$ individualnim iskanjem in pridobivanjem potrebnih informacij ter podatkov. Še posebej to velja za podjetja, katerih temeljna dejavnost so informacijski in/ali komunikacijski sistemi, in za katera je znano, da bodo uspešna le ob zagotavljanju znanja in njegovem učinkovitem obvladovanju. Tako je nujno potrebno iskati nove rešitve za podporo procesu izobraževanja, saj s konvencionalnimi pristopi/postopki ne moremo učinkovito odgovoriti na zahteve, ki prihajajo iz poslovnega sveta in jih narekujejo nova ekonomija, novi organizacijski pristopi ter čas, za katerega $\mathrm{v}$ poslovnem svetu še zmeraj in vedno bolj velja, da je denar.
Nataša Kegelj

Kovačič,

SRC.SI, d.o.o.

\section{SODOBNA POLITIKA} MENEDŽMENTA IZOBRAŽEVANJA ZAPOSLENIH IN PRISTOP $K$ OBVLADOVANJU AKTIVNOSTI IN PODATKOV O IZOBRAŽEVANJU V PODJETJU SRC.SI

Uspešnost menedžmenta bo zaradi vplivov globalizacije vse bolj odvisna od konkurenčnosti delovanja na mikro ravni, na katero izrazito vpliva kadrovski kapital, na celostni ravni pa vse bolj od izobraževanja kadrov kot osnovnega nosilca razvoja na področju kadrovskih virov (1), Danes tako več ne zadostuje izobraževanje glede na trenutne potrebe in želje, zato moramo znati (skušati) predvideti prihodnje spremembe in tudi prihodnje izobraževalne potrebe. Zaradi potrebe po razvoju konkurenčnosti se je treba lotiti 
Globalna konku-

renčnost zahteva

izobraževanje za

prihodnje potrebe. načrtnega razvoja kadrov $\mathrm{z}$ opredelitvijo strategije in njenega izvajanja. Tako je interes tistih podjetij, ki $v$ izobraževanje veliko in načrtno vlagajo, predvsem hitrejši povratni učinek izobraževanja na ekonomsko uspešnost podjetja.

$\mathrm{V}$ okviru sodobne politike menedžmenta izobraževanja kadrov govorimo predvsem o permanentnem izobraževanju, izpopolnjevanju in usposabljanju, zato je potrebno opredeliti razliko in povezanost med temi pojmi ${ }^{1}$.
Elektronsko obvladovanje izobraževanja je povezano še $\mathrm{z}$ ostalimi pomembnimi in ključnimi področji in predstavlja del aplikacije eHRM (aplikacija/elektronska podpora upravljanju kadrovskih virov), torej eHRM sistema, Ko govorimo o elektronski podpori upravljanju kadrovskih virov v podjetju, govorimo o procesih, aktivnostih, podatkih in informacijah, ki smo jih podprli oz. realizirali v elektronski obliki. Naša osnovna pričakovanja, ko smo se odločili za elektronsko podporo upravljanju kadrovskih virov, so bila povezana $\mathrm{z}$ ažurnostjo podatkov, informacijami, na osnovi katerih se lahko odločamo, upravljanjem procesa in povezovanjem $\mathrm{z}$ ostalimi procesi $\mathrm{v}$ podjetju. Sistem eHRM nam omogoča pretvoriti podatke $\mathrm{v}$ smiselne informacije, pretvoriti informacijo $\mathrm{v}$ znanje in ga povezati $\mathrm{z}$

Vprašanje, ali biti "učeče se podjetje", danes sploh ni več vprašanje, ampak nuja, pogoj za uspešnost in konkurenčnost podjetij. Podjetja se vsega tega zelo dobro zavedajo in $\mathrm{v}$ večini primerov tako tudi delujejo, nimajo pa urejene sistematične podpore oz. obvladovanja aktivnosti in podatkov, ki jih procesi in aktivnosti na področju izobraževanja nujno zahtevajo. vsebino procesa ter izmenjevati znanje $\mathrm{z}$ ostalimi udeleženci v procesu. $Z$ razyojem in uvedbo eHRM sistema smo zajeli vsa področja upravljanja kadrovskib virov: organizacijo podjetja, sistemizacijo delovnih mest, kadrovsko evidenco, razvoj kadrov, izobraževanje zaposlenih, letne pogovore, pridobivanje kadrov, načrtovanje odsotnosti, stroške dela in osebne strani zaposlenih. Tako smo dosegli popolno obvladovanje vseh potrebnih in pomembnih podatkov o podjetju, zaposlenih, delovnih mestih, izobraževanjih, odsotnostih, napredovanjih, dogodkih itd. Z možnostjo dodajanja alarmov in $s$ tem obveščanja ob različnih pomembnih aktivnostih in kreiranjem pregledov, poročil ter analiz je sistem postal najpomembnejši člen $v$ verigi upravljanja podjetja.

\section{ELEKTRONSKA PODPORA PROCESU IZOBRAŽEVANJA - VSEBINA TER PREDNOSTI IN CILJI UVEDBE APLIKACIJE}

Aktivnosti $v$ zvezi z izobraževanjem, tako planiranjem kot izvedbo, so ponavadi zelo različne. Pojavlja se več različnih akterjev v različnih časovnih obdobjih. Pojavlja se nešteto informacij in podatkov, kar je vse lahko obvladljivo le, če jih sistematično uredimo $v$ celoten cikel aktivnosti in obvladovanja podatkov. Še posebej smo to zaznali, ko se je število zaposlenih začelo mesečno spreminjati - povečevati. Tako smo v elektronski podpori izobraževanju ( $\mathrm{v}$ nadaljevanju: modul izobraževanje) vsebinsko oblikovali štiri različna področja izobraževanja, ki obstajajo v podjetju. Modul podpira vse postopke, povezane $\mathrm{z}$ načrtovanjem in obvladovanjem teh področij izobraževanja. Omenjena področja izobraževanja so:

- splošno (funkcionalno) izobraževanje,

- usposabljanje (pripravništvo, poskusno delo, prerazporeditev) ${ }^{2}$ 
- ciljno usposabljanje 2 in

- študij ob delu.

Modul izobraževanje nam omogoča:

- ustvarjanje letnih planov za izobraževanje načrtovanje sredstev in vsebine (strateška, ključna in podpornă znanja) glede na enote, delovna področja ter posamezne zaposlene,

- spremljanje izvajanja plana in porabe namenskih sredstev,

- prijavo na izobraževanje,

- odobritev izobraževanja,

- izvedbo izobraževanja,

- zbiranje odzivov in učinkovitosti izobraževaInih programov (ankete, ocene, poročila),

- posredovanje pridobljenih informacij in znanj med zaposlenimi (učeče se podjetje),

- arhiviranje potrdil o udeležbi (certifikati).

Najpomembnejši cilj, ki smo ga z uvedbo aplikacije dosegli, je pregled nad vsemi znanji v podjetju - imamo pregled nad intelektualnim kapitalom v podjetju.

\section{Splošno izobraževanje}

\section{Opis primera - postopek prijave na izobraževanje}

Postopek, ki je v podjetjih ponavadi dolg in zajema veliko papirja ter podatkov, je postopek prijave na izobraževanje in izvedbe izobraževanja. Ta postopek smo sistematično uredili z modulom, poimenovanim Prijaynica na izobraževanje, ki omogoča vse zapise o aktivnostih $v$ zvezi $\mathrm{z}$ določenim izobraževanjem zaposlenega, torej od načrtovanja, prijave, spremljanja udeležbe na izobraževanju do obračuna stroškov. Faze postopka prijave so vidne s prehodi med statusi: $v$ pripravi, prijava odobrena, prijava izyršena, prijava neizvršena, zaključeno ali neudeležba. Pri prijavi, ki je lahko izdelana že v letnem planu ali pa jo zaposleni (neplanirano) izdela med letom, je v prijavnici za izobraževanje potrebno izpolniti podatke o zaposlenem in podatke o izobraževanju, ki se izbere iz šifranta. Tako izdelana prijavnica mora $v$ "odobritev" k nadrejenemu, ki ga zaposleni izbere s seznama. Vodja ima v prijavnici možnost, da vidi vse podatke o določenem izobraževanju: ali je bilo planirano, stroške, datum udeležbe, tip in vsebino izobraževanja, kraj izobraževanja, izvajalca, določi mu lahko tudi pogodbeno obveznost itd. Odobritev je možna na dveh vodstvenih ravneh - neposredni vodja in direktor oz. predsednik podjetja. Tako zagotovimo vodstvu hiter in lahek pregled nad planirani$\mathrm{mi}$ in izvedenimi izobraževanji. Vse aktivnosti, ki se

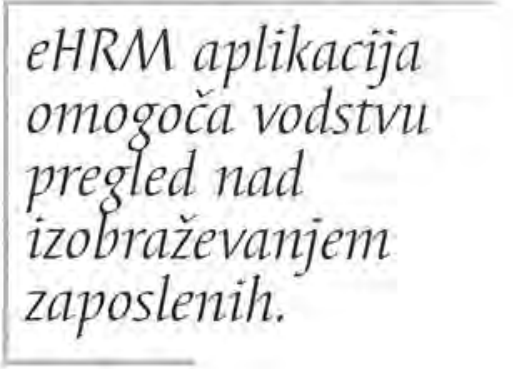
zgodijo, se v prijavnici tudi samodejno zapisujejo. Ko se status na prijavnici spremeni v "prijava izvršena", je na prijavnici možno obračunati stroške. Na tak način smo pridobili natančen in ažuren pregled nad porabo planiranih in porabo neplaniranih stroškov (možen je ločen pregled). Preden se prijavnica zaključi (torej se status spremeni $\mathrm{v}$ "zaključeno" in se izobraževanje upošteva kot "izvedeno"), mora zaposleni izdelati dodatne zapise na prijavnici, in sicer poročilo, preprost zapis, ki od uporabnika zahteva opis $\mathrm{v}$ tekstni obliki ali $\mathrm{v}$ obliki pripete datoteke ter anketo, ki je popolnoma nastavljiv zapis, na katerem si naročnik aplikacije po svoji lastni presoji oblikuje anketni list, ki je lahko sestavljen iz 10-ih zaprtih in 5-ih odprtih vprašanj. Na ta način smo zagotovili način za spremljanje učinkovitosti izobraževanja in evidentiranje vseh predlogov, ki jih zaposleni podajo po končani udeležbi. Namreč sistemi vodenja kakovosti, kot je na primer standard ISO 9001: 2000, vse bolj priporočajo, da se za vsako izvedeno izobraževanje preveri, ali je bilo učinkovito ali ne. Tako lahko vsak 
vodja za izobraževanje svojih podrejenih na posameznih prijavnicah $v$ seznamu, prirejenem za to funkcionalnost, označi, ali je bilo izobraževanje zelo učinkovito, učinkovito ali neučinkovito.

Kot pogoj za spremembo statusa v "zaključeno" je tudi arhiviranje in skeniranje potrdila o udeležbi oz. certifikata, ki je zelo pomemben dokument, še posebej v storitvenih podjetjih, kjer je potrebno dokazovati usposobljenost sodelavcev (reference). Z lahkim ukazom izbire in tiskanja lahko tako vsakdo kadarkoli kar najhitreje dobi dokument o usposobljenosti za kateregakoli zaposlenega (certifikat).

Ostala omenjena področja izobraževanja, ki jih ločujemo v SRC.SI - usposabljanje, ciljno usposabljanje in študij ob delu -, zajemajo druge aktivnosti in postopke ter so namenjena obvladovanju drugih postopkov in podatkov.

\section{Usposabljanje}

Je namenjeno obvladovanju vseh aktivnosti in informacij $\mathrm{v}$ zvezi $\mathrm{z}$ usposabljanjem na posameznem delovnem mestu ali skupini

\section{Pripravništvo se} spremlia s pomočjo računalniškega programa. delovnih mest za področja pripravništva, poskusnega dela ali prerazporeditve. $V$ teh aktivnostih sodelujeta zaposleni in nadrejeni, ko na osnovi pripravljenega programa usposabljanja spremljata opravljene aktivnosti znotraj plana. Za sam program je zadolžen mentor, zaposleni (ali pripravnik) na usposabljanju ga samo pregleduje. Zaposleni oz. pripravnik je dolžan v opredeljenih obdobjih (dnevna, tedenska, mesečna ...) izdelovati posamezna poročila, mentorjeva naloga pa je, da ta poročila pregleduje in jih odobri. Za vsakega zaposlenega, ki bo $v$ procesu uvajanja, se pripravi/izpolni tako imenovana "napotnica", ki vsebuje vse podatke, potrebne za spremljanje

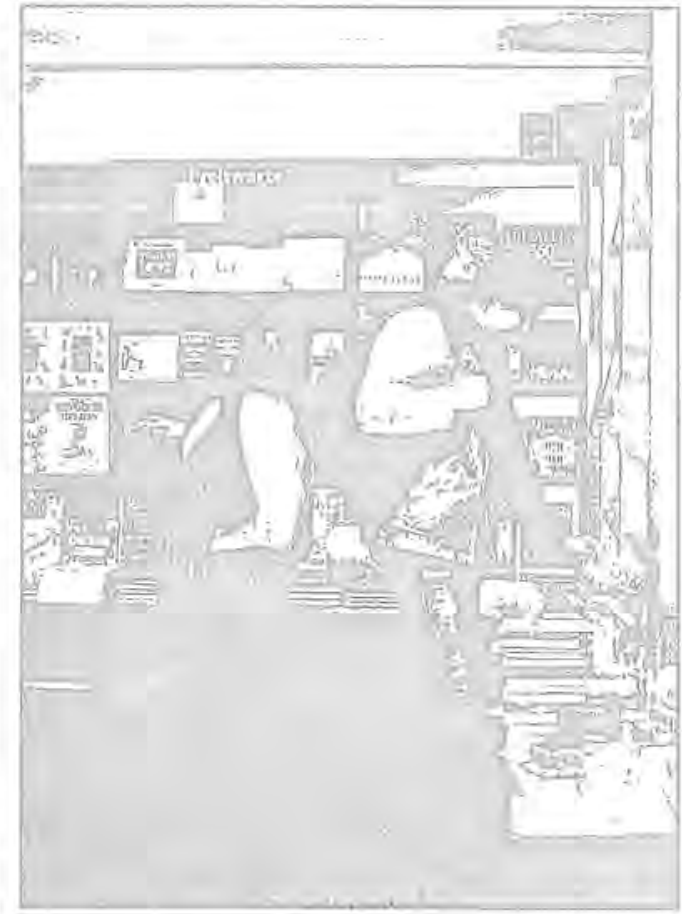

in preglede, ter ocene, torej podatke o zaposlenem, ki se bo usposabljal, o vrsti usposabjjanja (pripravništvo, poskusno delo ali prerazporeditev), o delovnem mestu, za katerega se bo usposabljanje izvajalo, o mentorju, terminu trajanja usposabljanja, o programu usposabljanja, zapis o tem, ali je zaposleni opravil usposabljanje ali ne, datum preskusa znanja (če je potreben) itd. Vsako takšno napotnico je možno natisniti z namenom, da jo mentor in zaposleni podpišeta in $\mathrm{s}$ tem potrdita seznanitev in strinjanje $\mathrm{z}$ vsebino ter prevzemata odgovornosti za njeno izvedbo.

\section{Ciljno usposabljanje}

Modul je namenjen spremljanju usposabljanja zaposlenih za določeno delo, naloge in preverjanju znanja. Postopek je podoben kot pri usposabljanju, le da gre v tem primeru za usposabljanje za točno določeno delo, ki je novo za zaposlenega, za usposabljanje posameznih dodatnih opravil (večopravilnost) ali za obnovo usposabljanja oz. izpita (recerti- 
ficiranje), Napotnico pripravi strokovni sodelavec v kadrovski službi, ki po predhodnem dogovoru določi mentorja (trenerja) in mu napotnico posreduje v elektronski obliki. Vodja v okviru napotnice pripravi program, ki se ponavadi za vsa delovna mesta in naloge nahaja v šifrantui, možno pa je dodati novega ali obstoječega spremeniti oz. prilagoditi. Za celotni zapis je zadolžen mentor (trener), zaposleni ga pregleduje in spremlja. Napotnica ima vlogo zapisovanja vseh aktivnosti in spremljanja opravljenih aktivnosti znotraj pripravljenega programa. Zaposleni je dolžen izdelovati zapise, poročila o posameznih opravljenih delih, ki jih je opravljal v obdobju ciljnega usposabljanja. V kakšnih obdobjih jih mora izdelovati, je določeno in vidno na napotnici (določi mentor), mentorjeva naloga pa je, da ta poročila pregleduje in jih odobri. Ob zaključku usposabljanja mora mentor zapisati datum, od katerega naprej je zaposleni usposobljen za opravljanje opravila. Iz šifranta se izračuna datum naslednjega preverjanja znanja, ki služi kot pravočasno alarmiranje o ponovnem preverjanju znanja. Ob koncu usposabljanja se napotnica natisne, da jo mentor in zaposleni lahko podpišeta.

Podoben postopek se opravi tudi v primeru preverjanja znanj (recertificiranja), ko se namesto programa usposabljanja vpiše le preverjanje znanja; to pomeni, da se posamezna usposabljanja glede na določeno obdobje preverjajo oz. recertificirajo. Tako se lahko samodejno izračuna datum preverjanja znanja za določeno delo. Po preteku določenega obdobja in v vsakem trenutku je možno s seznama recertificiranja dobiti seznam zaposlenih, ki jih je potrebno v posameznem mesecu recertificirati oz. nas na to lahko opozarjajo alarmi, če so nastavljeni v modulu "Alarmi".

Razliěni statusi napotnice kadrovski službi in vodstvu podjetja sproti prikazujejo stanje o tem, kako posamezna ciljna usposabljanja napredujejo.

\section{Študij ob delu}

Je namenjen obvladovanju vseh aktivnosti in informacij $v$ zvezi s strokovnim izobraževanjem - študijem določenega zaposlenega. Omogoča spremljanje vseh podatkov o zaposlenem, šolski organizaciji, smeri študija, datumu začetka študija, predvidenem datumu zaključka študija, datumu podpisa pogodbe (če podjetje krije stro-
Na obvezno (re)certificiranje znanja nas opozori računalnik. ške šolnine), številu dni študijskega dopusta, številu izpitov, tipu šolanja, pridobljeni stopnji izobrazbe, pridobljenem poklicu itd. Aplikacija nam omogoča tudi spremljanje evidene o študijskih dopustih (naziv izpita, datum od do, število dni porabljenega dopusta), stroških študija (naziv stroška, tip stroška, datum stroška, znesek stroška) in opravljenih izpitih (zapis, v katerega se vpisuje vsak posamezni opravljeni izpit ali pa ob koncu šolskega obdobja zapišemo število vseh opravljenih izpitov). Da bi bile informacije o zaposlenih $\mathrm{v}$
Izobrazba in dosežena znanja se ažurno shranjujeevidenci posameznika. jo $v$ racunalniski celotnem sistemu eHRM čim popolnejše, predvsem o izobrazbi, se ob zaključku študija posameznega zaposlenega sproži funkcionalnost, ki strokovnega delavca (oz. osebo, ki vnaša podatke) vpraša, če želi, da se končana izobrazba zapiše $v$ modul "Kadrovska evidenca". Tako se lahko takoj zavede zapis o spremembi končane izobrazbe določenega zaposlenega v splošnem modulu "Kadrovska evidenca" in je $\mathrm{z}$ enim vnosom urejena in izvedena popolna ažurnost podatkov o zaposlenih.

\section{PREDNOSTI ELEKTRONSKE PODPORE PROCESU IZOBRAŽEVANIA}

Najpomembnejše prednosti elektronske pod- 
pore na področju izobraževanja, ki smo jih pridobili $\mathrm{z}$ uvedbo aplikacije $\mathrm{v}$ delovno okolje, so:

- učinkovitejše načrtovanje izobraževalnih vsebin in razvoj kadrov,

- hitrejše pridobivanje informacij in podatkov za načrtovanje, izvedbo in odločanje za izobraževanje,

- ažurnost podatkov,

- lahek in pregleden način spremljanja stanja na področju izobraževanja,

- možnosti za hiter vpogled in izdelovanje poročil in analiz (pomembno za vodstvo),

- dostopnost podatkov vsem zaposlenim in neposrednim vodjem ter vodstvu,

- hitrejša izvedba postopkov pred izvedbo izobraževanja in po izvedbi izobraževanja,

- vodenje evidence o stanju dogodkov in arhiviranje vseh aktivnosti,

- v proces so vključeni zaposleni in njihovi neposredni vodje - hitro in lahko komuniciranje,

- hitro in lahko obvladovanje (z enim klikom spremenimo oz. uredimo cel cikel podatkov),

- pomembna obvestila in potrjevanja potekajo samodejno preko e-pošte,

- povečanje dinamike poslovanja,

- povečanje zadovoljstva zaposlenih,

- povečanje produktivnosti,

- zmanjšanje količine "papirjev".

\section{SKLEPNE MISLI}

V času globalizacije je ključna sposobnost vsakega podjetja hitro prilagajanje spremembam. S tem je povezan tudi največji izziv za sistem upravljanja zaposlenih in menedžment izobraževanja. Klasični, tradicionalni pristopi obvladovanja vseh aktivnosti, ki potekajo v procesu izobraževanja, so že pred leti zahtevali prenovo ali vsaj pre- oblikovanje, zato je danes samo še vprašanje časa, kdaj bodo tudi tista podjetja, ki temu ne dajejo posebnega poudarka oz. to prelagajo na "nekoč, potem", spoznala nujnost tega in se začela prilagajati potrebam konkurenčnega okolja.

\section{VIRI IN LITERATURA}

Regvar, B. (2001). Management in globalizacija. Zbornik posvetovanja z mednarodno udeležbo 200I. Kranj: Univerza v Mariboru, Fukulteta za organizacijske vede, str. 3.

Halal, E. Williams (1996). The New Management, Democracy and Enterprise are Transforming Organizations, San Francisco: Berett-Koehler Publishers.

Jereb, J. (1998). Izobraževanje in usposabljanje kadrov. Management kadrovskih virov. Ljubljana: Fakuiteta za družbene vede.

Zakrajšsek, M. (2003). Upravljanje človeških virov. Ljubljana: InfoSRC.SI, 2003/35, str. 7-8.

http://www.src.si/ponudba/ehrm.asp

1. Izobraževanje je dolgotrujen in načrten proces razvijanja posameznikovega znanja, sposobnosti in navad.

Izpopolnjevanje vkljuçuje procese dopolnjevanja. spreminjanja in sistematiziranja ze pridobljenega znanja, spretnosti, navad in wazirih sposobnosti.

Usposabljanje je proces razvijanja tistih posameznikovih sposobnosti, $\mathrm{ki}$ jih posanueznik potrebuje pri opravljanju konkretnega dela v okviru določene dejavnosti. (def. Jereb, .I.)

${ }^{2}$ Razlika med usposabljanjem in ciljnim usposabljanjem. je y namenu. Namen usposabtjanja je usposabljanje zaposlenega za opravljanje vseh del na delovnem mestu, ki ga zaseda. Običajno se zaposleni za eno delovno mesto usposablja v začemem obdobju njegove razporeditve na to delovno mesto. Namen ciljnega usposabljanja pa je usposabljanje za točno določeno delo oz nalogo. Zato je skozi ciljno usposabljanje poleg. samega usposabljanja možno spremljati ndi preverjanje znanja za posamezno opravilo. 